\title{
Development of the WBL System to Complement Lectures for Teacher Professional Development
}

\author{
Yusuke Morita \\ Nagasaki University \\ Faculty of Education \\ 1-14 Bunkyo, Nagasaki 852-8521, Japan \\ ymorita@i.edu.nagasaki-u.ac.jp \\ Naoto Sone \\ Naruto University of Education \\ Information Processing Center \\ naosone@ naruto-u.ac.jp
}

\author{
Norifumi Mashiko \\ Naruto University of Education \\ Faculty of School Education \\ 748 Takashima, Naruto 772-8502, Japan \\ mashiko@naruto-u.ac.jp \\ Ayako Kawakami \\ Naruto University of Education \\ Faculty of School Education \\ kawakami@naruto-u.ac.jp
}

\begin{abstract}
In this study, a Web Based-Learning system to complement lectures for teacher professional development was developed and evaluated by five points of view.The WBL courses using prior inference task were developed by Mashiko (2001) to exploit the lectures. The system including the courses had three function modes, (1) administrator mode, (2) learners mode and (3) instructor mode, are integrated using RDBMS. The learners estimated usefulness and practicability of the system for professional development of teachers especially the interaction in the online asynchronous forum with the face pictures of learners was valued.
\end{abstract}

\section{Introduction}

It is important to develop quality courses for professional development of teachers as in-service training in distance education. Mashiko et al. [2] developed Web-Based Learning courses using "prior inference task" to retrain teachers in the Graduate School of Education at Naruto University of Education(NUE), one of the public institutions providing retraining programs for teachers in Japan. This WBL system was also developed to complement lectures.

Levin et al. [1] identified five dimensions that contributed to effective online learning for teachers' professional development as follows: (a) relevant and challenging assignments, (b) coordinated learning environments, (c) adequate and timely feedback from instructors, (d) rich environments for student-to-student interaction, and (e) flexi- bility in teaching and learning. The purpose of this research was to develop WBL system where teachers can discuss online their practical experience and knowledge about computers and other subject areas. They can access information and make inquires to develop the best practice.

\section{Development}

The WBL system was constructed from free software (OS: Debian GNU/Linux kernel 2.4.14, HTTP Server: Apache 1.3.17, Streaming Server: RealServer 8, RDBMS: PostgreSQL7.0.2, Script Language: PHP4.0 and Perl5) for "(e) flexibility in teaching and learning." In the system, three function modes, (1) administrator mode, (2) learners mode and (3) instructor mode, are integrated using RDBMS.

(1)Administrator mode: In the administrator mode, a WBL system administrator can register personal information about learners and instructors, and can also open or close the courses when learners access or leave the system through the Internet/Intranet.

(2)Learner mode: In the learner mode, a learner can access some course materials, see profiles of other learners who attend the same course, discuss assignments using online asynchronous forum, and transmit reports to instructors. Special features are following. The system automatically identifies successful transmission when the learner submits a report to an instructor using the system. And a still digital picture of each learner is displayed on the forum pages to give the discussions a more personal feeling. Therefore, the forum provides 
“(d) rich environments for student-to-student interaction."

(3)Instructor mode: In the instructor mode, an instructor can survey data records of each learner in the courses covered by the instructor on this system. Instructors can also evaluate learners' reports, and the instructor can input comments which appear in each learner's private feedback box.

The instructor needs the instructor mode to "(b) coordinate learning environment" and to provide "(e) flexibility in teaching and learning." The WebCT, the most famous WBL system, has a designer mode which assists instructors in constructing online courses, however, instead of our system replaces the designer mode.

\section{Evaluation}

\subsection{Method}

Subjects: 11 subjects ( 8 teachers and 3 graduate students) participated in this test.

Lectures: From October to November 2001, the system using prior inference tasks for "(a) relevant and challenging assignments" complemented the lecture, 'Practical contents development.' One of the in-service teachers at Nagasaki University took the lecture through the Internet using live streaming video and NetMeeting for interactive communication with other learners on another campus. The instructor led them to accomplish tasks using text, pictures, and/or multimedia contents by SMIL (Synchronized Multimedia Integration Language). All of the learners connected to the system through the Internet/intranet after the lecture, in order to browse complementary instruction and discuss asynchronously with other learners in the forum. The instructor provided "(c) adequate, timely and meaningful feedback" and also promoted learners' discussion about the assignments.

Data: A questionnaire was used and data of learning records were analyzed to evaluate the system. The mean scores were calculated on the total number of 11 responses on a scale of $1-4$, with 1 representing "strongly disagree" and 4 indicating "strongly agree."

\subsection{Results}

Figure1 shows the items of the questionnaire and the mean scores. All scores were higher than 2.5 (mid value on a scale of 1-4). "Intelligibility of the instructor's explanations" scored 3.41. Furthermore, learners evaluated instruction in the forum, usefulness of showing face pictures, and effectiveness of displaying the information of leaning records.

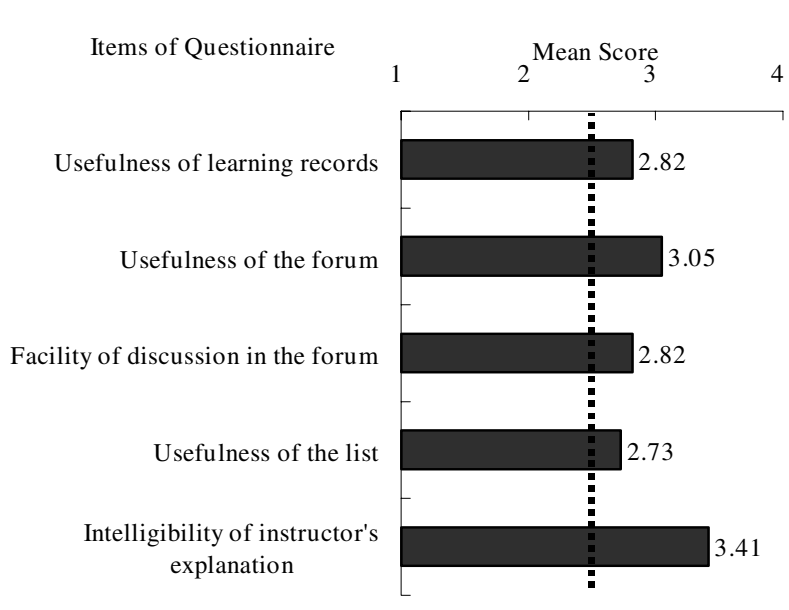

Figure 1. Evaluation of WBL System

On the other hand, Pearson's correlation coefficients between the number of ideas input by each learner, teaching careers, and access time from login to logout were calculated to analyze learners' behavior in the forum. The number of ideas on the forum correlated significantly with the careers in teaching $(\mathrm{r}=0.44)$, and also correlated with the access time $(\mathrm{r}=0.86)$. The instructor suggested many ideas and guided the discussion more than learners did in the forum.

\section{Conclusion}

In this study, we developed a WBL system for professional development of teachers. The system was evaluated from five points of view, which were as follows: (a) relevant and challenging assignments, (b) coordinated learning environment, (c) adequate and timely feedback from instructors, (d) rich environments for student-to-student interaction, and (e) flexibility in teaching and learning by Levin et al [1]. The learners estimated usefulness and practicability of the system for teacher professional development.

\section{References}

[1] S. R. Levin, G. L. Waddoups, J. Levin, and J. Buell. Highly interactive and effective online learning environment for teacher professional development. International Journal of Educational Technology, 2(2):http://www.outreach.uiuc.edu/ijet/v2n2/slevin/index.html, 2001.

[2] N. Mashiko, H. Sako, M. Umezawa, K. Nishioka, Y. Morita, and $\mathrm{H}$. Kuzukami. Linking educational practice research and university lecture improvement under promoting it education in public schools. Research Bulletin of Educational Sciences in Naruto University of Education, 17:57-64, 2002. 